UDK 781:001.8

Marija Bergamo

Filozofska fakulteta Univerze v Ljubljani

Faculty of Arts, University of Ljubljana

\title{
Glasboslovni instrumentarij v času premen znanstvenih obrazcev
}

\section{The Musicological Apparatus in Times of Changing Scholarly Models}

Ključne besede: muzikologija, estetika, teorija, analiza

POVZETEK

Prispevek obravnava položaj glasboslovne stroke in njenih orodij glede na zapletenost konteksta (širšega, t.i. stvarnosti in ožjega, strokovnega), v katerem ji je delovati in napredovati. Kot ovire (tako za umetniško delo kot za oblikovanje znanstvene disciplinarne matrice) izpostavlja razsrediščenost naravnega okolja, v katerem ni zaslediti enovitejšega nazora, obstoj različnih, posamičnih kontekstov in, posledično, izločenih teoretičnih polj. Tudi glasboslovje zajemajo procesi dehomogenizacije, izgube zgodovinskega spomina in konstruiranja problemov, ki ne izhajajo iz vitalnih nalog stroke. Včerajšnjo estetsko refleksijo, v kateri se prežemata teoretična bit znanosti in estetska bit umetnosti, danes nadomešča komaj pregledna ponudba teoretičnih sistemov, modelov, analitičnih metod. Teorije se ukvarjajo druga $z$ drugo, bolj kot s fenomeni, ki naj bi jih razlagale. Pri tem se pogosto prezrejo tiste teoretične podmene in zasnove, ki so vkomponirane $\mathrm{v}$ glasbeno deli in $\mathrm{v}$ njem presnovljene. Teorija pogosto sama gradi tako nalogo kot tudi instrumentarij za njeno razreševanje. Tudi muzikologija vse bolj postaja avtoreproduktivna in avtoreferencialna znanost. Perspektive? Na svoji nadaljnji poti bo gotovo morala ponovno najti pot do prvotnega, organskega glasbenega impulza, ki naj bi vodil misel o glasbi. Oprla naj bi se tudi na novopridobljeno pravico do osebnega odzivanja na pojave, do in-
Keywords: musicology, aesthetics, theory, analysis

SUMMARY

The article deals with the position of musicology and its apparatus with regard to the complicated context (broader, so-called reality, and narrower, relevant to the subject) within which it is to operate and develop. As obstacles (both for artistic work as well as for establishing a scholarly matrix), a dissociated natural milieu is brought forward in which neither uniform concepts nor the existence of various individual contexts, and, consequently, eliminated theoretical fields can be detected. Musicology as such is also being infected by processes of dehomogenization, of loss of historical memory, and of creating problems that do not arise from the vital tasks of the discipline. Yesterday's aesthetic reflection, in which the theoretical essence of scholarship and the aesthetical essence of art pervaded each other, is nowadays being substituted by a hardly surveyable supply of theoretical systems, models, and analytical methods. Theories deal with each other rather than with the phenomena that should explain them. Many a time those theoretical hypotheses and dispositions that have materialized in individual compositions remain all but overlooked. Theories themselves often set up problems as well as the apparatus needed for their solution. Musicology too is becoming a more and more selfreproductive as well as self-referential discipline. Perspectives? In its further development it will cer- 
terpretacije kot temeljnega glasbenega operativnega načela, celo do znanstvene avanture kot posledice silovite osebne izkušnje $z$ umetnostjo. Vendar se dvom $v$ možnost ponovne vzpostavitve trdnejšega referenčnega sistema in enovitejšega pogleda na celoto zdi še nadalje upravičen. tainly have to find its way back to the original, and organic, musical impulse that should lead our thinking on music. It should also be based on the newly acquired right to personal response as regards individual phenomena, to one's own interpretation as a musically basic operational principle, and even to scholarly adventures resulting from one's impetuously subjective experiences with art. However, a shadow of doubt about the possibility of renewing a firmer referential system and a more uniform view on integral wholes appears to be justified for the time being.

O vprašanjih iz naslova ne razmišljam prvič. Dolgo trajanje v stroki te, po eni strani, naredi za pričo tokov, ki danes že sodijo v zgodovino; tak položaj ti dovoljuje lasten pogled na stvari. Po drugi strani pa ti izostri občutljivost za vprašanja, ki segajo globlje od površja (tudi strokovnega) vsakdana, od prevelike zaupljivosti v dejstva in $\mathrm{v}$ prikupne, navidezno dokončne rešitve.

V gorišču mojega današnjega premisleka je položaj glasboslovne stroke in njenih orodij, glede na zapletenost konteksta $\mathrm{v}$ katerem poskuša delati in napredovati.

Ta kontekst naj ponazorita, - najprej na ožjem, umetniškem področju - dva zgovorna toposa:

1. Boris Groys je lani, ob obisku v Ljubljani, v razgovoru za Delo dejal, da "odnos do sodobne umenosti pomeni zgolj to, da te je umetnost zmedla, da ti spodnaša tla, da nisi prepričan ali veš za kaj gre, in da zgolj skušaš dojeti in sprejeti stvari kakršne so. Sodobna umetnost bega. A če bi vedeli kaj se dogaja, ne bi bilo več zanimivo... Umetnost kot socialno-politični in kulturni fenomen je kratkega daha in morda smo že na koncu tega fenomena. Ali pa tudi ne, pravzaprav ne vem." ${ }^{1}$

2. V uvodnem besedilu zbornika z naslovom Rethinking Music, ki ga je 1. 1999 uredil Nicholas Cook, sklene Philip Bohlmann svoje razmišljanje o ontologiji glasbe $z$ mislijo, da je "glasba lahko le to, kar mislimo, da je; lahko pa to tudi ni. Kaj glasba je, ostaja odprto vprašanje v vsakem času in v vsakem prostoru.. Urednik pa je $\mathrm{v}$ predgovoru previdno namignil, da bi bilo najenostavneje ugotoviti, da je "glasba prav tisto, kar mislimo, da je ${ }^{2}{ }^{2}$

Gre za posrečena domisleka ali za dejansko stanje stvari?

Prej drugo, glede na to, da širši, življenjski kontekst, ti. stvarnost, kljub (navidezni) pripravljenosti za sporazumevanje, izpričuje stanje splošnega nesporazuma. Umevanja in občutenja tega danes nihajo od trditev o koncu zgodovine, o koncu velikih povesti, o koncu ideologije, preko postavk o prehodni dobi (kot da ne bi bila vsaka doba po svoje prehodna!), do teze o vzvišenem kaosu, ki da tu in tam kaže na nov, drugačen, do potankosti še nepojasnjen red. Očitno je, da mislimo in govorimo iz

\footnotetext{
1 Teržan, Vesna: Pogovor z Borisom Groysom: V vlogi sodobnega Sokrata sprašuje: kaj je to, kar gledamo?, Delo, 30. 4. 2001.

2 Cook Nicholas, Everist Marc (ur.): Rethinking Music, Oxford University Press, 1999.
} 
stališča ti. živetega časa, ki zakriva izide prihodnje usode. Francoski literarni teoretik Paul Ricoeur ga poimenuje predfiguracija. ${ }^{3}$

Morebiti bo šele pogled iz vizure zgodovinskega časa, iz figuracije, s pregledom nad zaključenim obdobjem kot celoto zmogel urejujoče opredeliti pojave in spremeniti umevanje današnjega položaja, čeprav v to dvomim.

$\mathrm{V}$ očitni mentalni zmedi se pogledi ne morejo osrediščiti. Nekoč samoumevni, za določen čas in prostor vsaj do določene stopnje enotni nazor, je vedno fungiral kot nekakšno naravno okolje tako za umetniško delo, kot za znanstvene disciplinarne matrice. Današnja splošna razsrediščenost botruje rojevanju različnih, posamičnih kontekstov, iz katerih tudi teoretični nastavki črpajo svoje zasnove in pomene, ustvarjajo izločena teoretična polja. Teorije (tudi glasboslovne) se eventualno dotikajo druga druge, morda spletajo v mreže, ne zmorejo pa zajeti celote ali se o njej dogovoriti. $\mathrm{V}$ mislih mi je Openheimer, ki je diagnosticiral propad fizike, ko je ugotovil, da več ne ve kaj počne njegov kolega fizik v sosednji sobi.

Iz nezmožnosti dogovora o izhodiščnih opornih točkah se luščijo procesi dehomogenizacije strok, $\mathrm{z}$ močnimi nasprotovanji v akademskih skupnostih. Zaznamujejo jih praviloma krčenja podmen do preohlapnih poenostavitev, neodločnost pri izboru orodij, konstruiranje problemov, ki ne izhajajo iz dejanskih, vitalnih vprašanj in nalog stroke. Take tokove posebej boleče spremlja izguba zgodovinskega spomina, ki je danes nevarno zajela vsa področja duha. Kako obvladati sedanjost, če ne obvladamo preteklosti in njenih izkušenj?

Glasboslovno področje, ki nujno vključuje to širše obzorje in je njegov del, izkazuje enako zapletenost. Narava njegovega predmeta jo le še stopnjuje. Temeljna umeščenost stroke hkrati $\mathrm{v}$ dno in $\mathrm{v}$ vrh Aristotlove piramide, se pravi v čutno izkušnjo in hkrati logiko ter metafiziko ji nalaga nenehno posredovanje med znanstvenim in umetniškim, miselnim in čustvenim. Tak položaj ji - kot tudi nekaterim drugim znanostim o umetnosti - onemogoča vzpostavitev trdne znanstvene paradigme, v tistem smislu kot znanstveno paradigmo opredeljuje Thomas Kuhn, namreč kot "konceptualno in metodološko jedro, ki je skupno vsem članom znanstvene skupnosti v svojem času “. ${ }^{4}$ Morda bi - pogojno - lahko govorili o nekakšni disciplinarni matrici, po definiciji "skupni lasti praktikantov strokovne discipline". V njenem zavetju so namreč na voljo simboli, modeli in vzorčni primeri za razrešitev posamičnih vprašanj. Identiteto muzikologije pravzaprav zagotavlja le disciplinarni okvir s svojo pahljačo načel, možnosti in tehnik za opazovanje in razumevanje fenomenov. Disciplinski okvir nadomešča nekdanjo Kantovsko regulativno idejo, ki je utemeljevala cilje in metode muzikologije v 19. in začetku 20. stoletja. Od Adlerjevega zaupanja v možnost vzpostavitve najvišjih zakonov umetnosti ni ostalo veliko. Njegova dihotomična razdelitev muzikološkega področja na historični del (katerega naloga je zbrati dejstva) in sistematični (ki naj bi iz teh dejstev izluščil večne zakonitosti) je bila nekoč tako prepričljiva in učinkovita, da podtalno živi še danes. Tudi v razmerah, ko se nismo dogovorili niti o opredelitvi glasbenega dejstva, kaj šele o načinih njegove razlage.

3 Ricoeur, Paul: Temps et récit 1-3, 1983-85, Paris, cit. po Biti,Vladimir: Pojmovnik suvremene književne teorije, Matica Hrvatska, Zagreb 1997, p.96.

${ }^{4}$ Ule, Andrej: Sodobne teorije znanosti, ZPS, Ljubljana 1992, p.144-150. 
Če je do včeraj veljalo (zame velja še danes), da se v muzikološki estetski refleksiji srečujeta in prežemata teoretična bit znanosti in estetska bit umetnosti, je v množini današnje glasboslovne bere razmerje drugačno. Že glasba sama, od časa modernizma, in tudi v ti. postmoderni, obstaja prej v mediju misli kot pa občutenja. Rojeva se kot articifielni konstrukt, osvobojena pomenov in neposrednih učinkov. Težko funkcionira brez ustrezne in iz nje največkrat izhajajoče parcialne teorije. Brez tega spremstva in opreme je ne razumemo. Redko je namenjena našemu občutenjskemu in doživljajskemu svetu.

Današnja, komaj pregledna ponudba glasboslovnih teoretičnih sistemov, modelov, pomensko skrčenih vzorcev, analitičnih metod in (posamičnim poddisciplinarnim področjem zavezanih) predlogov pojasnjevanja glasbenih pojavov, izvira iz temeljne okoliščine, ki zaznamuje današnji položaj muzikologije: namreč, da se teorije nanašajo in navezujejo druga na drugo in ukvarjajo druga $z$ drugo, prej kot pa $s$ fenomeni, katere naj bi razlagale. Tako se pogosto dogaja, da ostanejo ob strani tiste teoretične podmene in zasnove, ki so vkomponirane $\mathrm{v}$ samo glasbeno delo in $\mathrm{v}$ njem presnovljene. Ne opazimo jih ali pa zamolčimo, če ne prispevajo potrditvi verodostojnosti teorije, oz. modela, ki smo si ga izbrali za interpretacijo skladbe. Večkrat si teorija sama zastavlja nalogo in izbira instrumentarij za njegovo razreševanje. Glasbena dejstva in pojavi se tako znajdejo na Prokrustovi postelji namenov, načrtov in zahtev teorije, namesto pred razumevajočim pogledom občutljivega raziskovalca.

Zato tudi muzikologija postaja danes vse bolj avtoreproduktivna in avtoreferencialna znanost, razsrediščena in razdrobljena, potujena in samovšečna. Še tako vedoželjnega porabnika zajetna glasboslovna ponudba sicer priteguje, vendar hkrati prepričuje, da njene nore progresije tako in tako ne more obvladati. Sprašujem se večkrat, kje je tisti organski glasbeni impulz, ki je znal sprožati in voditi misel o glasbi?

$\mathrm{S}$ tem ne izpričujem dvoma $\mathrm{v}$ teorijo. Nasprotno. Tudi ne $\mathrm{v}$ upravičenost različnih teoretičnih sistemov. Ne mislim, da bi vsi morali (ali mogli) biti splošno uporabni in enakovredni. Vendar bi morali izkazovati zadovoljive algoritme, merila, ki informacijam zagotavljajo vrednost. Kot tudi možnosti za vsaj delno medsebojno komuniciranje, da bi se njihovi uporabniki lahko razumeli.

Na kaj bi se torej v času znanstvenega "mnogoboštva" zmogel ópreti glasboslovni instrumentarij?

Najprej na dejstvo, da se človekova narava (še) ni bistveno spremenila. Glasba je nepogrešljiv del človekove emocionalne inteligence, zdravilna oaza živega duha $\mathrm{v}$ obmrli kulturi. Identiteta glasbe same se namreč - ne glede na načine opazovanja - v svoji temeljni podstati ne spreminja. (Celo v aktualni, danes modni Luhmannovi teoriji sistemov, se umetniško delo opredeljuje kot strnjen in klen načrt za večkratno uporabo; zunajčasouna tvorba se, po Luhmannu, zaporedoma hrani s temporaliziranimi postopki lastnega opazovanja.) Skladbo pravzaprav opredeljujejo v njej kodirana umetniška vprašanja in načrti, enkratni izbor konstelacij in zvez, ki jih poskušamo analitično zajeti, dojeti in razložiti. Ne opisovati, temveč estetsko rekonstruirati.

Pomoč nam ponuja zavedanje, da je tudi muzikološko delo procesualnega značaja, da je naše opazovanje glasbenih umetnin na sebi dinamično in da, v procesu približevanja muzikološko delo samo svoj predmet v določenem smislu dograjuje ali spre- 
minja. V današnjem spopadanju teorij, ki zagovarjajo red, s tistimi, ki navezujejo na predočbo kaosa in njegove nelinearne urejenosti, prav tako opazujemo nenehno spreminjanje, dynamis, dogajanje, tudi dopolnjevanje.

Izguba trdnejšega skupnega veljavnega disciplinarnega nazora je sprožila spremembo razmerja do subjekta in subjektivnega $\mathrm{v}$ znanosti. Celo $\mathrm{v}$ zgodovinskih razpravah, kjer smo še do včeraj vztrajali na, vsaj navidezni, akademski objektivnosti, se danes osebnostno obarvanemu delu odpirajo nove možnosti. Objava lastnega izhodiščnega in metodološkega stališča ter kriterijev odločanja pri selektiranju dejstev razkriva pogledu Drugega tudi mentalni ustroj raziskovalca, razloge in pota njegovega zasledovanja začasne resnice, njegove resnice. Dovoljeni so mu dvomi, omahovanja, neodločnost. Nevarnost novega položaja se v našem času vznapredovale stopnje estetske demokracije (kot ga prizanesljivo vidi Peter Sloterdijk) sicer kažejo v skrajnostih preosebnih in preohlapnih razlag, ki same na sebi nosijo postmoderni pečat. Vendar take stroka kot neuporabne spotoma izloča.

$\mathrm{Z}$ novopridobljenimi pravicami osebnega odzivanja na umetniške pojave, se tudi v glasboslovni vedi - preveša nekdanji poudarek s spoznavnega vidika na interpretativni. Stališče, da stvarnosti pravzaprav ni izven subjekta, oz. njegovega pogleda, ker jo le-ta šele konstituira, - postavlja interpretacijo za temeljno glasboslovno operativno načelo. Seveda se hkrati zastavlja vprašanje zagotavljanja, oz. preverjanja širše veljavnosti in uporabnosti izidov interpretacije. Richard Rorty ${ }^{5}$ predlaga postopek pregovarjanja, ki naj bi se izteklo v dogovor o tem, kako vzpostaviti nekakšno središče interpretacije, določeno soglasje na ravni nadrejene, začasno sprejete matrice, kot pogoja sporazumevanja. Takšno orodje bi bila na našem strokovnem področju danes estetika, pretolmačena in utemeljena kot interpretativna disciplina. Razlage umetnosti sicer mnogi teoretiki vidijo le kot parazitski diskurz samih razlagalcev, ki navadno z umetnostjo niso v nikakršnem stiku. O tem smo že spregovorili. Ker pa so na drugi strani še vedno razlagalci starejšega kova kot jih imenuje Albrecht Riethmüller, ${ }^{6}$ ki še znajo pričati o sreči srečanja $z$ umetnostjo, se skupaj z njim odločam za slednje. Človek je tako in tako, po sebi hermenevtičen; $z$ vsem, kar izpoveduje razlaga - posredno ali neposredno - samega sebe.

V stroki naj bi bila danes dovoljena, celo dobrodošla, tudi znanstvena avantura. Mislim pri tem na tisto obliko doživljanja, ki se zna pretakati tudi po znanstveniških žilah: kot močna energija, skorajda presežek življenske energije, se tu in tam prenese tudi na znanstveno gradivo in se nato iz njega spet črpa. Predmetu raziskave je lahko le v prid. Navidezna nečistost znanstvenega dela, se v takih primerih zna obrestovati. Silovita osebna izkušnja $z$ umetnostjo tedaj namreč zmore premostiti odmik od predmeta. Tudi muzikološki izdelek lahko postane estetičen. Glasboslovna teorija si namreč $\mathrm{v}$ postmodernem času tudi sama pogosto privzema značilno distanco do sebe same, podedovano od glasbenega modernizma. Spodbudno alternativo je videti v temeljni

5 Rorty, Richard: Contingency, Irony and Solicianty, Cambridge, cit. po Biti, Vladimir: Strano tijelo pri/povijesti, Hrvatska sveučilišna naklada, Zagreb 2000, p. 126.

6 Riethmüller, Albrecht: Interpretation in der Musik, v: G. Funke - A. Riethmüller - O. Zwierlein: Interpretation, Stuttgart 1998 , p. 18. 
drugačni opremljenosti našega uma: v čustveno-zaznavno dejavni mreži posamične muzikološke zavesti, ki zmore razgibati ali sprostiti ustvarjalne moči in se z lastnim talentom dotakniti skladateljeve zavesti. Karl Popper te moči poimenuje z intelektualno intuicijo ${ }^{7}$. Opredeljuje jo kot občutenje, ki je praviloma izid daljšega analitičnega opazovanja pojava in nato procesa povezovanja delov v celoto. Predlaga celo, da bi intenziteto tega občutenja jemali za mero in merilo resničnosti, oz. veljavnosti misli, ki so ga sprožile. Pri našem delu je ustvarjalna intuicija danes še kako dobrodošel instrument. Od nekdanjih odvetnikov preteklosti postajamo vse bolj reševalci ugank, raziskovalci, ki naj bi $\mathrm{z}$ lastno občutljivostjo izsledili perceptivno, čustveno in sistemsko kodo drugega.

Glasba, razen tega - bolj dejavno in globlje kot katera koli druga umetnost - tipa v področjih še ne obstoječe stvarnosti. Sluti prihodnost, uvaja pogojni red v kaotično, zakrito področje možnega. Slediti temu prevajanju možnega v urejeno strukturo sodi - med najbolj vznemirljive in najodgovornejše muzikološke naloge. Tako včeraj, kot danes. Ali tudi jutri? Nisem prepričana, da tudi jutri ...

Končno: današnji postmoderni svet zahteva tudi od glasboslovca, da pri svojem delu upošteva ves ti. svet umetnosti, (sintagmo predlaga Miško Šuvakovicic ob sklicevanju na Dantojevo izhodišče). Povezovanje umetniških fenomenov in umetniške prakse, obzorje, ki vključuje paradigme in posamičnosti, strukture in zgodovino, danes botruje prežemanju teorije in umetnosti, njunemu medsebojnemu sokonstituiranju. Estetika kot interpretativna disciplina pa naj bi bila tisti prehod, ki omogoča prehajanje od enega $\mathrm{k}$ drugemu in gibanje med deli tega sveta umetnosti.

Morda se prav v tem predlogu, - ob ohranjanju in razvijanju omenjene pristne umetniške občutljivosti glasboslovca, - skriva droben up v ( $\mathrm{z}$ današnjega vidika sicer paradoksalno) restavracijo soglasja o pogledu na celoto, up v dogovor o trdnejšem referenčnem sistemu, ki bi tudi naši stroki omogočil lažje delo in plodovitejše izide.

7 Cit. po Engel, Gerhard: Musik und Wissenschaft, Frankfurt a.M. 1980, p. 17-19.

8 Šuvaković, Miško: Pojmovnik moderne i postmoderne likovne umetnosti i teorije posle 1950., SANU/Prometej, Beograd-Novi Sad 1999, p. 325-327. 